\title{
The AAA+ ATPases and HfIB/FtsH Proteases of 'Candidatus Phytoplasma mali': Phylogenetic Diversity, Membrane Topology, and Relationship to Strain Virulence
}

\author{
Erich Seemüller, ${ }^{1}$ Sandor Sule, ${ }^{2}$ Michael Kube, ${ }^{3}$ Wilhelm Jelkmann, ${ }^{1}$ and Bernd Schneider ${ }^{1}$ \\ ${ }^{1}$ Institute for Plant Protection in Fruit Crops and Viticulture, Julius Kuehn Institute, D-69221 Dossenheim, Germany; ${ }^{2}$ Plant \\ Protection Institute, Centre for Agricultural Research of the Hungarian Academy of Science, H-1525 Budapest, P.O. Box 102, \\ Hungary; ${ }^{3}$ Department of Crop and Animal Sciences, Division of Phytomedicine, Humboldt University, Lentzeallee 55/57, \\ D-14195 Berlin, Germany
}

Submitted 17 September 2012. Accepted 31 October 2012.

\begin{abstract}
Previous examination revealed a correlation of phytopathogenic data of 'Candidatus Phytoplasma mali' strains and the DNA sequence variability of a type ATP00464 $h f l B$ gene fragment. To further investigate such a relationship, all distinct genes previously annotated as $h f l B$ in the genome of ' $\mathrm{Ca}$. P. mali' strain AT were fully sequenced and analyzed from a number of representative mild, moderate, and severe strains. The re-annotation indicated that the sequences encode six AAA+ ATPases and six HflB proteases. Each of the nine distinct deduced AAA+ proteins that were examined formed a coherent phylogenetic cluster. However, within these groups, sequences of three ATPases and three proteases from mild and severe strains clustered distantly, according to their virulence. This grouping was supported by an association with virulence-related amino acid substitutions. Another finding was that full-length genes from ATPase AP11 could only be identified in mild and moderate strains. Prediction of the membrane topology indicated that the long ATPase- and protease-carrying C-terminal tails of approximately half of the $\mathrm{AAA}+$ proteins are extracellular, putatively facing the environment of the sieve tubes. Thus, they may be involved in pathogen-host interactions and may compromise phloem function, a major effect of phytoplasma infection. All full-length genes examined appear transcriptionally active and all deduced peptides show the key positions indicative for protein function.
\end{abstract}

Phytoplasmas are uncultivated bacterial plant pathogens of the class Mollicutes characterized by small genomes (530 to $1.350 \mathrm{~kb}$ ) and a low $\mathrm{G}+\mathrm{C}$ content (21.4 to $29.5 \%)$. They are transmitted from plant to plant by phloem-feeding insects such as leafhoppers, planthoppers, and psyllids and are associated with diseases of some 1000 plant species (Seemüller et al.

Corresponding author: E. Seemüller;

E-mail: erich.seemueller@jki.bund.de

Full-length strain sequences of AAA+ ATPase genes AP11, AP39, AP406 and AP460 and $h f l B$ genes AP34, AP273, AP382, AP457 and AP464 are available in the GenBank, EMBL, and DDBJ databases under accession numbers HE819246 to HE819291 and HE819292 to HE819349, respectively.

* The $e$-Xtra logo stands for "electronic extra" and indicates that four supplementary tables are published online.

(C) 2013 The American Phytopathological Society
2002). Many of them, including apple proliferation (AP), are of considerable economic importance. Like all phytoplasmas, the AP agent resides in plants exclusively or predominantly in sieve tube elements of the conducting phloem tissue (Siller et al. 1987). Previous work on diseased apple and pear trees has shown that the function of the secondary phloem may be severely affected by the infection. Severe histopathological symptoms such as callose deposition and sieve tube necrosis were observed in susceptible genotypes. The impaired phloem transport leads to the accumulation of starch in the aerial parts of the trees and depletion of starch in the roots and may result in decline of the trees (Batjer and Schneider 1960; Blodgett et al. 1962; Kartte and Seemüller 1991).

Little is known about the molecular mechanism of ' $C$ andidatus Phytoplasma mali'-induced disease. However, an involvement of the protein encoded by $h f l B$ gene ATP00464 was recently suggested by comparing phytopathogenic data of ' $\mathrm{Ca}$. P. mali' accessions from 27 symptomatically different apple trees and the corresponding single-strand conformation polymorphism profiles and DNA sequences of a variable fragment of this gene. Phylogenetic comparison of the $h f l B$ gene sequences of the various strains revealed that mild and severe strains cluster separately, according to their virulence (Seemüller et al. 2011). hflB (synonym $f t s H$ ) genes encode membraneassociated ATP- and $\mathrm{Zn}^{2+}$-dependent proteases that are conserved among bacteria and degrade misassembled and shortlived proteins, thus enabling cellular regulation at the level of protein stability and contributing to quality maintenance of proteins in the membrane and cytoplasm. They are characterized by a transmembrane region, ATPase domains, and a protease module (Ito and Akiyama 2005).

In the four completely sequenced phytoplasma genomes, between six and 24 copies of $h f l B$ genes have been annotated (Arashida et al. 2008; Bai et al. 2006; Kube et al. 2008; Oshima et al. 2004; Tran-Nguyen et al. 2008). On the ' $\mathrm{Ca}$. P. mali' strain AT chromosome (GenBank accession number CU469464.2), 12 full-length or truncated $h f l B$ genes were annotated previously and were assigned to three groups of paralogs (ATP00011, ATP00406, ATP00460, and ATP00487; ATP00034, ATP00454, ATP00457, and ATP00464; and ATP00039 and ATP00146) and the orthologs ATP00273 and ATP00382 (Kube et al. 2008). The transcription of ATP00034, ATP00464 (Schneider and Seemüller 2009), ATP00146, ATP00406, and ATP00460 (M. Kube, unpublished results) has been identified. The high copy number of $h f l B$ genes in phytoplasmas is unusual in other prokaryotes, including the close 
phytoplasma relative Acholeplasma laidlawii (GenBank accession number CP000896.1), which has only one $h f l B$ gene. Although the abundance of $h f l B$ genes in phytoplasmas seems to indicate their importance for these plant pathogens, it is not clear whether they are involved in parasitism. The ATP00464 $h f l B$ gene investigated in our previous study encodes a putative protein of 599 amino acid residues that is anchored to the cytoplasm membrane via two transmembrane segments, with the short $\mathrm{N}$ - and long $\mathrm{C}$-terminal part facing the cytoplasm. The main cytosolic region consists of an ATPase associated with various cellular activities (AAA+ protein) composed of an AAA+ ATPase and a $\mathrm{Zn}^{2+}$ metalloprotease (Schneider and Seemüller 2009; Seemüller et al. 2011). This data may suggest that the ATP00464 protein is essential for cellular function but may not directly be involved in pathogenicity. However, from Staphylococcus aureus and Salmonella enterica, there is indication that, by action of $\mathrm{HflBs} / \mathrm{FtsHs}$, pathogenicity can be affected by attenuating virulence (Alix and Blanc-Potard 2008; Lithgow et al. 2004). Similar effects cannot be excluded for the AP phytoplasma.

To further investigate the possible role of HflBs in the virulence of ' $C a$. P. mali', we amplified and sequenced all distinctly different genes previously annotated as $h f l B$ in strain AT from a number of representative mild, moderate, and severe isolates. Based on the data obtained, we reannotated the genes and determined the diversity and homology among the genes and the deduced proteins. In order to examine the phytopathologic relevance of the AAA+ proteins, the deduced amino acid sequences of strains differing in virulence were analyzed for clustering behavior and relevant substitutions. In addition, the putative spatial orientation of the long C-terminal tails was assessed using two prediction systems to obtain information about whether the catalytic domains of the AAA+ proteins are cytosolic or extracellular.

\section{RESULTS}

\section{Strain virulence and}

\section{polymerase chain reaction amplification.}

Twenty ' $\mathrm{Ca}$. P. mali' strains maintained in apple or periwinkle (Catharanthus roseus) and tobacco (Nicotiana occidentalis)

Table 1. 'Candidatus Phytoplasma mali' strains examined

\begin{tabular}{|c|c|c|}
\hline Strain & Geographic origin & Virulence (score) ${ }^{\mathrm{a}}$ \\
\hline $1 / 93 \mathrm{Vin}^{\mathrm{b}}$ & Burgundy (France) & Mild (0.1) \\
\hline $1 / 93 \mathrm{Tab}^{\mathrm{c}}$ & Burgundy (France) & Mild (0.1) \\
\hline $2 / 4$ & Dossenheim & Mild (0.2) \\
\hline $2 / 7$ & Dossenheim & Mild (0.2) \\
\hline $3 / 1$ & Dossenheim & Severe (3.0) \\
\hline $3 / 2$ & Dossenheim & Mild (0.1) \\
\hline $3 / 3$ & Dossenheim & Mild (0.2) \\
\hline $3 / 5$ & Dossenheim & Severe (3.0) \\
\hline $3 / 6$ & Dossenheim & Severe (3.0) \\
\hline $3 / 8$ & Dossenheim & Moderate (2.4) \\
\hline $8 / 7$ & Dossenheim & Moderate (1.8) \\
\hline $12 / 93$ & Dossenheim & Severe (3.0) \\
\hline AP15 ${ }^{\mathrm{d}}$ & Udine (Italy) & Severe $(2.6)^{\mathrm{e}}$ \\
\hline $\mathrm{AT}^{4}$ & Heidelberg & Moderate $(2.4)^{\mathrm{e}}$ \\
\hline AT-2 & Trento (Italy) & Moderate (2.3) \\
\hline GDH1 & Dossenheim & Severe (2.7) \\
\hline GDH4 & Dossenheim & Severe (2.8) \\
\hline GDH6 & Dossenheim & Severe (2.6) \\
\hline Rol & Heidelberg & Moderate (2.4) \\
\hline WS & Dossenheim & Severe $(2.8)$ \\
\hline
\end{tabular}

\footnotetext{
a Score: 0 , no symptoms to 3 , severe symptoms.

b Maintained in apple and Catharanthus roseus.

${ }^{c}$ Maintained in apple and Nicotiana occidentalis.

${ }^{\mathrm{d}}$ Maintained in $C$. roseus and $N$. occidentalis.

e Estimated values from infection of experimental hosts.
}

were included in the study. From previous work, each of them was known to show a uniform phytoplasma population (Seemüller et al. 2010, 2011). Virulence of the material examined differed considerably and was assessed as being mildly, moderately, or severely virulent (Table 1).

Of the 12 genes previously annotated as $h f l B \mathrm{~s}$ in ' $\mathrm{Ca}$. P. mali' strain AT, 10 of them comprising ATP00011, ATP00034, ATP00039, ATP00273, ATP00382, ATP00406, ATP00454, ATP00457, ATP00460, and ATP00464 were amplified from other strains. They are referred to in the following as AP11 to AP464. Homologs of genes ATP00146 and ATP00487 were not included because they are, in the fully sequenced chromosome of strain AT, identical to their paralogs ATP00039 and ATP00011, respectively. Amplification of the selected genes from the various strains varied considerably, due to sequence variability in the intergenic regions or the adjacent genes. Some genes, such as AP39 and AP460, could be amplified from many strains with one primer pair. However, to obtain sufficient data necessary to examine sequence relationship and strain virulence, amplification of other genes, such as AP34 and 406, required up to six primer pairs (Supplementary Table S1). Gene AP406 could be amplified with one primer pair from all mild strains whereas several other pairs were necessary to amplify the gene from moderate and severe strains. Due to the difficulties in polymerase chain reaction (PCR) amplification, not always the same strains could be examined for the various genes.

\section{Molecular and phylogenetic features.}

BLAST searches with the PCR-amplified gene sequences and all genes of strain AT previously annotated as $h f l B$ revealed that the 12 genes consist of two groups. Six genes with sizes between 1,065 and 1,404 bp encode AAA+ ATPases and six genes with sizes between 1,797 and 2,061 bp encode HflB proteases (Table 2). Amplification of putative $h f l B$ gene AP454 resulted from all analyzed strains in truncated PCR products that consisted of 330- to 550-bp fragments of the $3^{\prime}$ end. They constituted the entire protease module or parts thereof whereas the ATPase domains and the transmembrane segments were missing. Sequence alignments revealed that the AP454 fragments are most closely related to sequences of paralog AP464 (data not shown). Another finding was that the full-length AP11 gene could only be amplified from all mild strains examined, tobacco-maintained strain AT, and moderate strains $8 / 7$ and AT-2. In contrast, only rudimentary, mostly approximately 150-bp-sized AP11-specific fragments from the $3^{\prime}$ end could be amplified from severe strains and some moderate strains (Fig. 1; data not shown). Similar-sized fragments in addition to full-length genes were observed in some samples from mild strains and moderately virulent strain 3/8 (data not shown).

Phylogenetic analysis of deduced full-length peptide sequences showed that the strain sequences of each AAA+ protein formed a coherent group that clustered in a distinct subclade. Distinct subclades were also formed by the members of the two major paralogous groups, consisting of ATPases AP11, AP406, and AP460 and HflBs AP34, AP457, and AP464, respectively (Figs. 2 and 3). The sequence identity between the proteins of these groups was 51.0 to $79.0 \%$. The phylogenetic distance between the orthologs AP273 and AP382 and between the orthologs and the paralogous groups (17.8 to $30.0 \%$ identity) was considerably greater. An exception was HflB AP273 that showed approximately 50\% sequence similarity with the group of paralogs represented by AP464 (Supplementary Tables S2 and S3). Because this value was similar to those in the group of paralogs represented by AP460, AP273 may be considered as a paralog of the AP464 group. 
Compared with the diversity between the AAA+ proteins, the strain sequences of each of these proteins formed quite homogeneous groups. A particularly high sequence identity (similarity values between 97.8 and $99.1 \%$ ) was shown by AP11, AP273, and AP457. With dissimilarities between 86.6 and $87.7 \%$, diversity was highest in AP406 and AP460 (Table 2). Despite the distinct clustering of the various proteins and their different variability, each of the two groups of proteins appeared to be functionally similar. In the protein-protein BLAST searches, all AAA+ ATPases were classified as typical members of the AAA+ superfamily that represent an ancient group of ATPases belonging to the additional strand, catalytic E division of the P-loop NTPase fold. They are molecular chaperons or ATPase subunits of proteases and other enzymes. The HflB proteases of ' $\mathrm{Ca}$. P. mali' are all members of peptidase family 41, superfamily cl03209, and are composed of the ATPase domains and a peptidase module.

In addition to the previously identified transcriptional activity of genes AP34, AP146, AP406, AP460, and AP464, transcription of genes AP11, AP39, AP273, AP382, and AP457 was shown in this study. All deduced full-length AAA+ proteins possessed the characteristic elements of the ATPase module, consisting of the Walker A and B domains, the pore region, sensor 1 and 2, and the second region of homology that includes the arginine finger. However, these motifs were polymorphic except for key positions that are crucial for protein function. For the AAA+ proteins of ' $C a$. P. mali', variability was observed mainly in the arginine finger and sensor 2 motifs of ATPases AP460 and AP39 and, to a lesser extent, in HflB AP382 (data not shown). However, highly conserved and functionally important key residues were present in all critical domains of the AAA+ proteins examined although, in some of these motifs, only one or two instead of two or three canonical key positions were present. The $\mathrm{Zn}^{2+}$ metalloprotease domain HEXXH, where $\mathrm{X}$ is any amino acid residue, was conserved in all HflBs of ' $\mathrm{Ca}$. P. mali'. The relevant AAA+ protein motifs of strain AT are shown in Table 3 as an example.

\section{Membrane topology and signal peptides.}

The Phobius predictor classified all AAA+ ATPases and HflB proteases of ' $\mathrm{Ca}$. P. mali' as integral membrane proteins. Membrane topology prediction indicated that all ATPases have a single transmembrane domain. A single segment was also predicted for the AP382 protease whereas all other HflBs have two domains (Table 4). Prediction of the spatial orientation of the catalytically relevant $\mathrm{C}$-tail suggested that this segment of AP457, AP464, and AP11 (including its paralog AP487 in strain AT) of all strains examined was facing the cytoplasm. In contrast, the C-tail of ATPases AP39/AP146 and AP460 and of proteases AP34, AP273, and AP382 was uniformly predicted to be extracellular. ATPase AP406 showed a different feature in that the C-tails of all mild strains, the two periwinkle-maintained strains AT and AP15, and moderate strain 8/7 were predicted to be cytoplasmatic whereas an extracellular orientation was predicted for all severe strains isolated from apple and moderate strain 3/8 (Table 4; data not shown).

The Phobius predictions were largely confirmed by the PolyPhobius approach that includes alignment information from related proteins in the assessment. Exceptions included mainly the extracellular orientation of the C-tail of all AP406 sequences whereas the C-tail of all HflB AP34 sequences and the AP273 sequence of mild strain 1/93Vin was predicted to be cytosolic (Table 4; data not shown). Analysis of the PolyPhobius prediction data indicated that these differences to the Phobius prediction were due to the strains selected by the program for comparison. For the AP406 proteins, mainly or exclusively closely related ' $\mathrm{Ca}$. P. mali' and ' $\mathrm{Ca}$. P. asteris' sequences characterized by extracellular C-tail orientation were selected. In contrast, mainly sequences of walled bacteria were used for the C-tail prediction of AP34 by the PolyPhobius program that were predicted by Phobius to have a cytoplasmatic C-tail.

Using the SignalP 4.0 software, signal peptides were only predicted for the AP39 protein of strains AT and 1/93. The probability scores for these proteins were just above the threshold of 0.45 , whereas the scores of the AP39 protein from

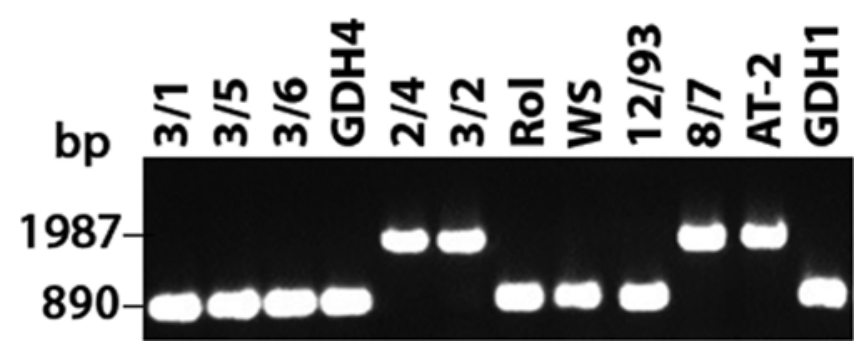

Fig. 1. Polymerase chain reaction amplification of AAA+ ATPase gene AP11 of 'Candidatus Phytoplasma mali' from severe (3/1, 3/5, 3/6, GDH4, WS, 12/93, and GDH1), moderately virulent (Rol, $8 / 7$, and AT-2), and mild (2/4 and 3/2) strains with primers binding in the flanking regions of the gene.

Table 2. Molecular features and phytopathogenic relationships of AAA+ ATPases and HflB proteases of 'Candidatus Phytoplasma mali' strains

\begin{tabular}{|c|c|c|c|c|}
\hline Protein & $\begin{array}{l}\text { Number of strain } \\
\text { sequences }\end{array}$ & $\begin{array}{l}\text { Amino acid } \\
\text { residues }\end{array}$ & $\begin{array}{l}\text { Protein identity } \\
\quad(\%)\end{array}$ & Phytopathogenic relationships \\
\hline \multicolumn{5}{|c|}{ AAA+ ATPase } \\
\hline AP11 & 14 & 421 & $99.1-100$ & $\begin{array}{l}\text { Full-size proteins only from mild and some moderate strains; } \\
\text { C-terminal fragments only from severe strains }\end{array}$ \\
\hline AP487 & 1 & 421 & & Identical paralog to AP11 in ' $\mathrm{Ca}$. P. mali' strain AT \\
\hline AP406 & 17 & $414-415$ & $87.7-100$ & $\begin{array}{l}\text { Virulence-related clustering; } 31 \text { virulence-related substitutions, mainly at } \\
\text { the N-terminus }\end{array}$ \\
\hline AP460 & 15 & $354-357$ & $86.6-99.7$ & $\begin{array}{l}\text { Virulence-related clustering; Severe strains differ mostly by seven } \\
\text { substitutions from mild strains }\end{array}$ \\
\hline AP39 & 11 & $463-470$ & $95.5-99.6$ & Virulence-related clustering; Severe strains share three substitutions \\
\hline AP146 & 1 & 470 & $\ldots$ & Identical paralog to AP39 in ' $\mathrm{Ca}$. P. mali' strain AT \\
\hline \multicolumn{5}{|r|}{ 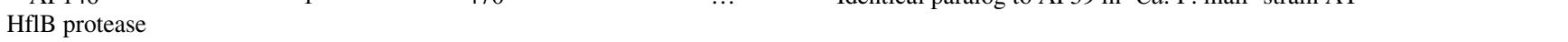 } \\
\hline AP34 & 10 & 600 & $96.2-99.8$ & $\begin{array}{l}\text { Virulence-related clustering and virulence-related substitutions; unique } \\
\text { 37-residue stretch in strain AT }\end{array}$ \\
\hline AP454 & 10 & $100-180$ & & C-terminal fragments only \\
\hline AP457 & 16 & $601-602$ & $97.8-100$ & No virulence-related clustering or substitutions \\
\hline AP464 & 16 & 599 & $96.3-100$ & $\begin{array}{l}\text { Virulence-related clustering and virulence-related substitutions; unique } \\
\text { 37-residue stretch in strain AT }\end{array}$ \\
\hline AP273 & 14 & $680-686$ & $97.9-100$ & No virulence-related clustering or substitutions \\
\hline AP382 & 17 & $598-626$ & $90.2-100$ & Virulence-related clustering and virulence-associated substitutions \\
\hline
\end{tabular}


other strains were below this threshold (Table 4). The Phobius software did not predict signal peptides in any sequence.

\section{Amino acid sequence and strain virulence of AAA+ ATPases.}

Comparison of strain virulence and phylogenetic clustering indicated a close relationship of these traits for most AAA+ ATPases (Table 2). All sequences from severe and mild strains of ATPases AP39, AP406, and AP460 clustered distantly (Fig. 2). Less unambiguous was the positioning of the moderately virulent strains 8/7, AT-2, and Rol and the periwinkle- and tobacco-maintained strain AP15 that clustered with either severe or mild strains. However, at least one sequence of each of these strains clustered with severe strains. An exception was

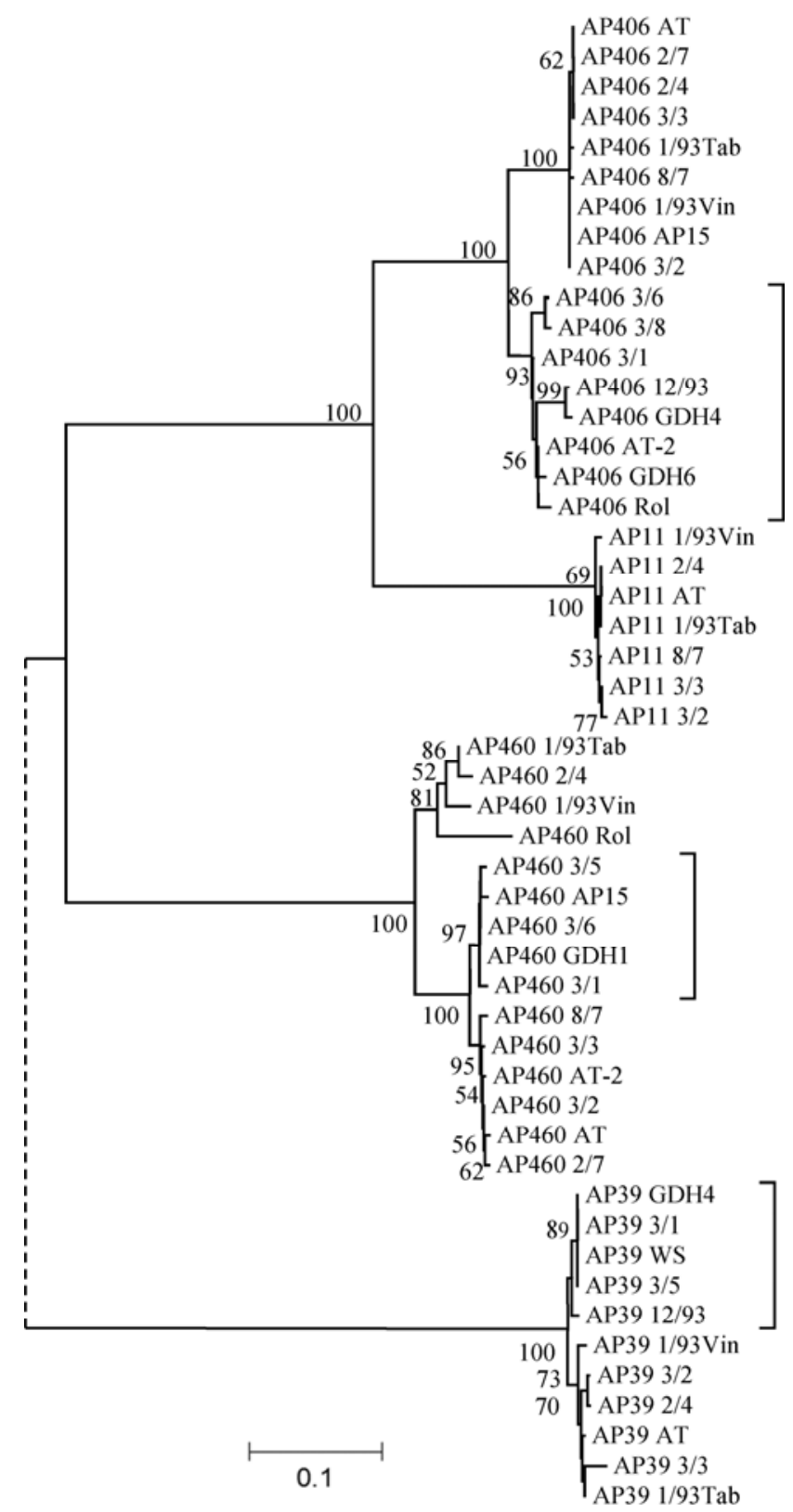

Fig. 2. Phylogenetic and phytopathogenic clustering of deduced amino acid sequences of AAA+ ATPases AP11, AP39, AP406, and AP460 of 'Candidatus Phytoplasma mali' from severe (3/1, 3/5, 3/6, 12/93, AP15, GDH1, GDH4, GDH6, and WS), moderately virulent ( $3 / 8,8 / 7$, AT, AT-2, and ROL), and mild (1/93Vin, 1/93Tab, 2/4, 2/7, 3/2, and 3/3) strains. Distant clustering of severe and moderately virulent strains is indicated by brackets. The length of the two major branches was cut for higher resolution of strain differences. Extensions of the protein names indicate strain designation. strain AT that always clustered with mild strains although it induced moderate symptoms in periwinkle and $N$. occidentalis. The full-length sequences of the putatively cytoplasmatic AP11 ATPase from mild and moderate strains were identical or nearly identical (Table 2).

The distinct clustering of the strains examined according to their virulence was linked to molecular markers at the deduced amino acid level. No virulence-related substitutions were identified in the sequences of protein AP11. By contrast, with the exception of moderate strain 8/7, the sequences of AP406 from severe and moderately virulent strains from apple differed from those of mild strains by 31 substitutions. Of these, 12 were located in the region from the $\mathrm{N}$ terminus to the transmembrane segment (Fig. 4). The remaining 19 substitutions occurred mainly in three groups. They included the Walker A and arginine finger motifs without affecting key residues. The sequences of the AP460 protein exhibited an overall diversity and distinct clustering similar to its paralog AP406. However, they showed only seven major substitutions at positions 262, 277, 278, 282, 296, 297, and 313 that distinguished nearly all severe strains from most mild and moderate strains. A deletion in severe strains at position 294 led to the loss of the $G$ residue in the canonical sensor 2 motif GAR, in which only the A residue remained. The AP39 sequences of severe strains differed from those of moderate and mild strains by substitutions at positions 30,31 , and 398, the former two being located in the transmembrane segment. In addition to the major substitution sites described, in ATPases AP39, AP406, and AP460 there were several single substitutions and small groups of replacements that only occurred in either severe or mild strains and contributed to the distant clustering.

Amino acid sequence and strain virulence of $\mathrm{HflB}$ proteases.

Compared with the ATPases, the relationship between the deduced amino acid sequence and strain virulence in the HflBs was less pronounced (Table 2). In the AP464 paralog group, the AP464 sequences from all severe and moderate strains as well as from periwinkle-maintained strain AP15 clustered in a different branch than those of mild strains (Fig. 3). They showed a single unique substitution at position 135 in the second transmembrane segment. In addition, strain AT showed a stretch of 37 residues close to the C-terminus with 13 unique substitutions (Fig. 5). AP34 sequences from severe strains clustered at two distant positions of the subtree and differed from all mild and moderate strains by a single substitution at position 428. Moreover, the AP34 sequence from strain AT showed the same unique 37-residue stretch close to the C-terminus as described for AP464 (Fig. 5). In contrast, the cytoplasmatic protease AP457 showed little sequence variability and no virulence-related clustering (Fig. 3).

The AP273 protease showed high sequence similarity over all strains (Fig. 3). Virulence-related clustering and substitutions were not identified. In contrast, AP382 sequences showed a considerably higher diversity, resulting in a distinct clustering of all severe and moderate strains, including periwinkle-maintained strain AP15 (Fig. 3). Moreover, all severe and moderately virulent strains, except for strain AT, showed virulence-associated substitutions between the protease motive and the C-terminus at positions $480,525,527$, and 570 . In addition to the major substitutions described for AP34, AP382, and AP464, there were several smaller groups of substitutions and single-residue replacements in these proteins in which severe and mild strains differed and which contributed to their distant clustering.

Rates of radical and conservative amino acid replacements.

The number of sites at which the amino acid residues of most or all severe strains differed from those of most or all 
mild strains was most pronounced in the ATPases AP406 and AP460 and in HflB protease AP382. For this reason, the relevant sites of these proteins were examined for the type of amino acid substitutions in more detail. Of the 31 substitutions in protein AP406, 12 were located at the $\mathrm{N}$ terminus (Fig. 4). Eleven of the latter group were radical replacements classified by volume and polarity ("polar replacements"). Five of them also were classified as radical replacements of the category characterized by charge differences ("charge replacements"). Of the remaining 19 substitutions, which mainly occurred in three narrow groups, 10 were radical polar replacements, of which six were also radical charge replacements. The seven major substitutions in the AP460 protein were located between position 262 and 313 and consisted of six radical polar replacements and four radical charge replacements.

The four major substitution sites of HflB protein AP382 occurred from position 480 to 570 and consisted of two conservative replacements and two radical charge and polar replacements. Of the 13 substitutions in the unique 37-residue stretch of strain AT at the C-terminus of the AP34 and AP464 proteins, 11 were radical polar replacements and 8 were also radical charge replacements. These data indicated a high number of radical substitutions. Of the 73 major substitution sites of AAA+ ATPases and HflB proteases of ' $\mathrm{Ca}$. P. mali' that were described in this section and in the two sections above, only $25 \%$ were conservative replacements whereas $75 \%$ were radical polar replacements and $49 \%$ were also radical charge replacements.

\section{DISCUSSION}

In plants, phytoplasmas cause a wide range of macroscopic symptoms on leaves, flowers, and fruit and in the growing habit. The formation of such mostly specific symptoms depends much on the host species or host genotype. In addition, there are nonspecific symptoms associated with most or all phytoplasmal diseases such as reduced vigor, low productivity of crop plants, stunting, and decline. This group of symptoms is usually attributed to the impairment of the sieve tube function. The drastic effect of the infection as evidenced by pathological callose deposition and sieve tube necrosis that leads to accumulation of carbohydrates, particularly starch, in source tissue of trees and depletion of starch in the roots is well documented (Batjer and Schneider 1960; Blodgett et al 1962; Braun and Sinclair 1976, 1978; Kartte and Seemüller 1991). Reduced contents of starch and soluble carbohydrates leading to growth inhibition were also identified in the roots of ' $\mathrm{Ca}$. P. mali'infected periwinkle and tobacco ( $N$. tabacum) plants (Lepka et al. 1999). Despite this data on the detrimental effect of infection on phloem function, little information is available on the molecular and physiological mechanisms behind this interaction.

The results of our work may allow new approaches to study the pathogenic action of phytoplasmas in sieve elements. The members of the two groups of AAA+ proteins analyzed in this work are phylogenetically diverse but appear functionally

Fig. 3. Phylogenetic and phytopathogenic clustering of deduced amino acid sequences of HflB proteases AP34, AP273, AP382, AP457, and AP464 of 'Candidatus Phytoplasma mali' from severe $(3 / 1,3 / 5,3 / 6$, 12/93, AP15, GDH1, GDH4, GDH6, and WS), moderately virulent (3/8, 8/7, AT, AT-2, and ROL), and mild (1/93Vin, 1/93Tab, 2/4, 2/7, 3/2, and $3 / 3$ ) strains. Distant clustering of severe and moderately virulent strains is indicated by brackets. The length of the two major branches was cut for higher resolution of strain differences. Extensions of the protein names indicate strain designation. similar. The AAA+ superfamily, to which both groups of proteins of the AP phytoplasma belong to, is a large group of enzymes that are able to induce conformational changes in a wide range of substrate proteins. The family's defining feature

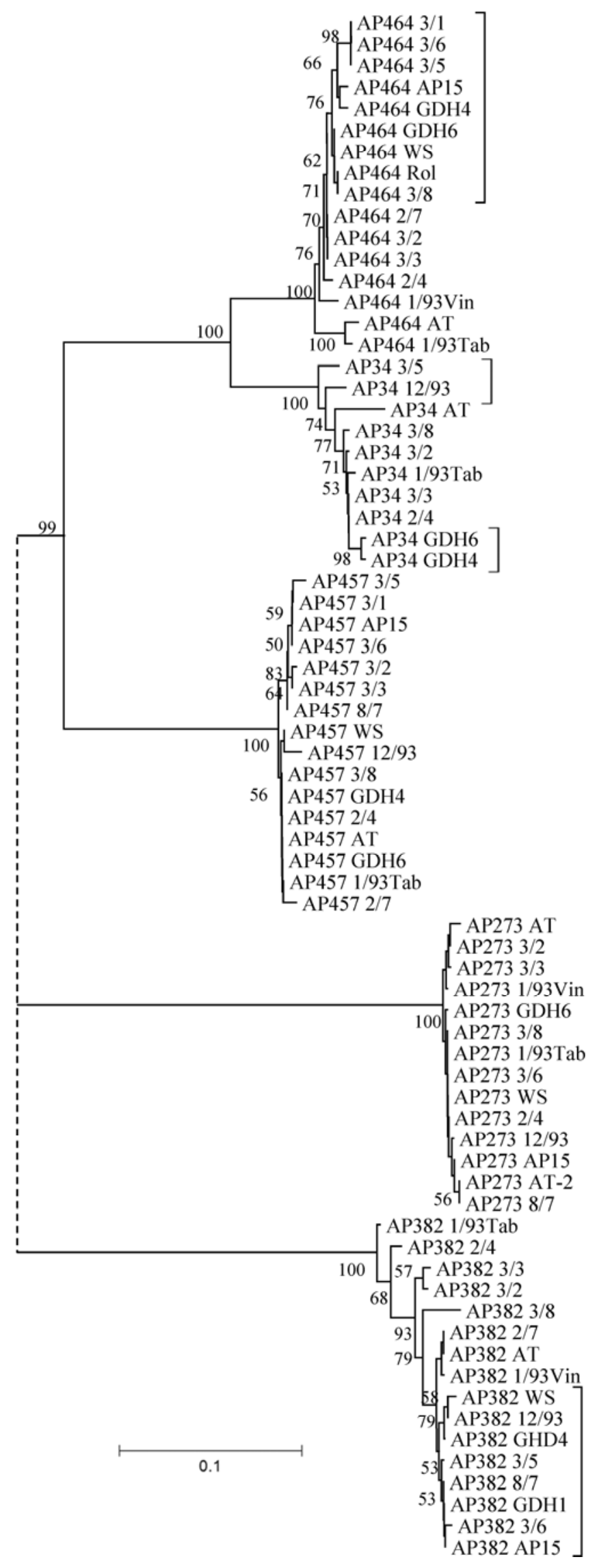

Vol. 26, No. 3, 2013 / 371 
is a structurally conserved ATPase domain that assembles into oligomeric rings and undergoes conformational changes during cycles of nucleotide binding and hydrolysis. Thus, these proteins are crucial for proteolysis, in which their role is to unfold substrates and deliver them to the active site of the protease module. In HflBs, the ATPase domains and the protease module are encoded in one polypeptide whereas, in most others systems, the two modules are encoded in separate polypeptides (Hanson and Whiteheart 2005; Snider et al. 2008). Although there is a considerable polymorphism in the typical ATPase motifs of the AAA+ proteins of ' $\mathrm{Ca}$. P. mali', key positions crucial for protein function were identified in all of them. Vir- tually all variations observed in our work are known from other $\mathrm{AAA}+$ proteins and seem not to affect function (Erzberger and Berger 2006; Hanson and Whiteheart 2005; Karata et al. 2001; Langklotz et al. 2012).

HflBs usually degrade short-lived proteins and misassembled membrane proteins, contributing to their quality maintenance. In addition, they have a special ability to dislocate membrane protein substrates out of the membrane, for which their own membrane-embedded nature is essential. Functional native protein substrates are susceptible to proteolytic action of HflBs in initiation-signal-dependent manners. This mode of proteolysis seems to involve sequential substrate unfolding,

Table 3. Characteristic domain motifs of AAA+ proteins of 'Candidatus Phytoplasma mali' strain AT

\begin{tabular}{|c|c|c|c|c|c|c|c|}
\hline Protein & Walker A & Pore & Walker B & Sensor 1 & ARG finger & Sensor 2 & Protease \\
\hline \multicolumn{8}{|l|}{ AAA+ ATPase } \\
\hline AP11/AP487 & $\mathbf{G}^{173} \mathrm{CPGTGKT}$ & $\mathrm{Y}^{206} \mathrm{RG}$ & $\mathrm{IFLD}^{236} \mathbf{E}$ & $\mathrm{T}^{282} \mathrm{NHI}$ & $\mathbf{R}^{\mathbf{3 1 1}} \mathrm{KER}$ & $\mathbf{G}^{346}$ ENS & $\ldots$ \\
\hline AP406 & $\mathbf{G}^{167}$ VPGTGKT & $\mathrm{Y}^{199} \mathrm{RG}$ & IFLD $^{229} \mathbf{E}$ & $\mathbf{T}^{275} \mathrm{NHI}$ & $\mathbf{R}^{\mathbf{3 0 0}} \mathrm{KER}$ & $\mathbf{G}^{339}$ ENS & $\ldots$ \\
\hline AP460 & $\mathbf{G}^{120}$ VAGTGKT & $\mathrm{Y}^{153} \mathrm{IG}$ & $\mathrm{IFLD}^{183} \mathbf{E}$ & $\mathrm{T}^{229} \mathrm{NHF}$ & KQDR $\mathbf{R}^{\mathbf{2 5 7}}$ & $\mathrm{DA}^{295} \mathrm{PE}$ & $\ldots$ \\
\hline AP39/AP146 & $\mathbf{G}^{\mathbf{1 6 2}} \mathrm{PPGTGKT}$ & $\mathbf{Y}^{184} \mathrm{TI}$ & $\mathrm{IFCD}^{\mathbf{2 1 3}} \mathbf{E}$ & $\mathrm{T}^{259} \mathrm{NYI}$ & ILSR $\mathbf{R}^{272}$ & $\mathrm{SA}^{350} \mathrm{ND}$ & $\ldots$ \\
\hline \multicolumn{8}{|l|}{ HflB protease } \\
\hline AP34 & $\mathbf{G}^{215}$ PPGTGKT & $Y^{248} V G$ & $\mathrm{LFID}^{274} \mathbf{E}$ & $\mathrm{T}^{320} \mathrm{NRA}$ & $\mathbf{R}^{332}$ PGR & $\mathrm{G}^{381} \mathrm{AQ}$ & $\mathbf{H}^{\mathbf{4 3 7}} \mathbf{E A G H}$ \\
\hline AP457 & $\mathbf{G}^{218}$ PPGTGKT & $\mathrm{Y}^{251} \mathrm{VG}$ & $\mathrm{LFID}^{277} \mathbf{E}$ & $\mathrm{T}^{323} \mathrm{NRV}$ & $\mathbf{R}^{335}$ PGR & $\mathrm{G}^{384} \mathrm{AQ}$ & $\mathbf{H}^{\mathbf{4 4 0}} \mathrm{EAGH}$ \\
\hline AP464 & $\mathbf{G}^{\mathbf{2 1 4}}$ PPGTGKT & $Y^{247} V G$ & $\mathrm{LFID}^{273} \mathbf{E}$ & $\mathrm{T}^{319} \mathrm{NRA}$ & $\mathbf{R}^{331} \mathrm{PGR}$ & $\mathrm{G}^{380} \mathrm{AQ}$ & $\mathbf{H}^{\mathbf{4 3 6}}$ EAGH \\
\hline AP273 & $\mathbf{G}^{272}$ PPGTGKT & $Y^{305} V G$ & $\mathrm{IFID}^{331} \mathbf{E}$ & $\mathrm{T}^{376} \mathrm{NQP}$ & $\mathbf{R}^{388}$ PGR & $\mathrm{G}^{437} \mathrm{AQ}$ & $\mathbf{H}^{493}$ ESGH \\
\hline AP382 & $\mathbf{G}^{106}$ PPGTGKT & $Y^{141} V G$ & $\mathrm{IFVD}^{173} \mathbf{E}$ & $\mathrm{T}^{221} \mathrm{NRE}$ & $\mathbf{R}^{233} \mathrm{SGR}$ & $\mathrm{PA}^{300} \mathrm{Q}$ & $\mathbf{H}^{360}$ ELGH \\
\hline
\end{tabular}

${ }^{a}$ Residues of high conservation and functional importance according to Hanson and Whiteheart (2005) and Ito and Akiyama (2005) are in bold.

Table 4. Prediction of spatial membrane topology and signal peptides of AAA+ proteins of 'Candidatus Phytoplasma mali' strains using Phobius, PolyPhobius, and SignalP predictors

\begin{tabular}{|c|c|c|c|c|c|}
\hline \multirow[b]{2}{*}{ Protein } & \multirow[b]{2}{*}{ Strain $^{b}$} & \multirow[b]{2}{*}{ Segment $^{c}$} & \multicolumn{2}{|c|}{ C-tail orientation, out $(\%)^{a}$} & \multirow[b]{2}{*}{ D score ${ }^{d}$} \\
\hline & & & Phobius & PolyPhobius & \\
\hline \multicolumn{6}{|l|}{ AAA+ ATPase } \\
\hline AP11 & $2 / 4(\mathrm{~m})$ & 1 & 15 & 40 & $1-550.120$ \\
\hline AP11, AP487 & $\mathrm{AT}(\mathrm{mo})$ & 1 & 15 & 40 & $1-550.120$ \\
\hline AP39 & 1/93Vin (m) & 1 & 90 & 90 & $1-310.475$ \\
\hline AP39 & $2 / 4(\mathrm{~m})$ & 1 & 78 & 82 & $1-360.406$ \\
\hline AP39 & $\mathrm{AT}(\mathrm{mo})$ & 1 & 90 & 90 & $1-310.475$ \\
\hline AP39 & GDH4 (s) & 1 & 75 & 85 & $1-310.403$ \\
\hline AP406 & 1/93Vin (m) & 1 & 28 & 61 & $1-310.100$ \\
\hline AP406 & $2 / 4(\mathrm{~m})$ & 1 & 28 & 61 & $1-170.154$ \\
\hline AP406 & $3 / 6(\mathrm{~s})$ & 1 & 65 & 70 & $1-90.114$ \\
\hline AP406 & $12 / 93(\mathrm{~s})$ & 1 & 65 & 72 & $1-90.117$ \\
\hline AP460 & 1/93Vin (m) & 1 & 85 & 80 & $1-00.108$ \\
\hline AP460 & $2 / 4(\mathrm{~m})$ & 1 & 85 & 80 & $1-00.108$ \\
\hline AP460 & $3 / 1(\mathrm{~s})$ & 1 & 80 & 75 & $1-00.113$ \\
\hline AP460 & $3 / 6(\mathrm{~s})$ & 1 & 80 & 75 & $1-00.113$ \\
\hline \multicolumn{6}{|l|}{ HflB protease } \\
\hline AP34 & $2 / 4(\mathrm{~m})$ & 2 & 80 & 25 & $1-10.283$ \\
\hline AP34 & $3 / 5(\mathrm{~s})$ & 2 & 90 & 30 & $1-10.273$ \\
\hline AP34 & GDH4 (s) & 2 & 80 & 25 & $1-10.273$ \\
\hline AP273 & 1/93Vin (m) & 2 & 65 & 45 & $1-380.209$ \\
\hline AP273 & $2 / 4(\mathrm{~m})$ & 2 & 85 & 85 & $1-380.212$ \\
\hline AP273 & $3 / 6(s)$ & 2 & 87 & 87 & $1-380.212$ \\
\hline AP273 & $12 / 93(\mathrm{~s})$ & 2 & 88 & 85 & $1-380.212$ \\
\hline AP382 & 1/93Vin $(\mathrm{m})$ & 1 & 98 & 72 & $1-00.116$ \\
\hline AP382 & 2/4 (m) & 1 & 100 & 80 & $1-00.116$ \\
\hline AP382 & $3 / 6(s)$ & 1 & 100 & 75 & $1-00.103$ \\
\hline AP382 & $12 / 93(\mathrm{~s})$ & 1 & 98 & 72 & $1-00.103$ \\
\hline AP457 & $2 / 4(\mathrm{~m})$ & 2 & 24 & 24 & $1-130.233$ \\
\hline AP457 & $3 / 6(s)$ & 2 & 25 & 25 & $1-130.233$ \\
\hline AP457 & AT (mo) & 2 & 20 & 20 & $1-130.233$ \\
\hline AP464 & $2 / 4(\mathrm{~m})$ & 2 & 3 & 0.02 & $1-10.311$ \\
\hline AP464 & $3 / 6(s)$ & 2 & 2 & 0.02 & $1-10.302$ \\
\hline AP464 & $\mathrm{AT}$ (mo) & 2 & 2 & 0.02 & $1-10.311$ \\
\hline
\end{tabular}

${ }^{\text {a }}$ Out $(\%)=$ probability of extracellular C-tail ( $>50 \%$ in bold).

${ }^{\mathrm{b}}$ Strain virulence: $\mathrm{m}$, mild; mo, moderate; and s, severe.

${ }^{\mathrm{c}}$ Transmembrane segments.

d SignalP 04 prediction, values for position and height of the cleavage site. Cut-off for AP39 and most other proteins $=0.45$. Predicted signal peptides are in bold. 
initiated by an initiation signal and then propagated along the polypeptide chain (Ito and Akiyama 2005). Some nonsubstrate membrane proteins can also be converted into HflB substrates when they are altered to contain a tail of sufficient length (Chiba et al. 2002).

In relation to pathogenesis, only a few reports have linked $\mathrm{HflB} / \mathrm{FtsH}$ to virulence. It could be shown that the virulence factor MgtC of Salmonella enterica may be degraded by action of this protein (Alix and Blanc-Potard 2008). On the other hand, mutation of ftsH in Staphylococcus aureus may lead to pleiotropic defects by affecting several physiological and biochemical processes and attenuating pathogenicity (Lithgow et al. 2004). Other work revealed that unassembled SecY, which forms a stable translocon complex with SecE and SecG, may be digested by action of HflB, leading to the compromised permeability barrier of the membrane in Escherichia coli (Akiyama et al. 1996). These examples indicate weakening of the pathogenic fitness of the microbes that may also apply for the action of cytosolic AAA+ proteins of ' $\mathrm{Ca}$. P. mali' .

$\mathrm{AAA}+$ proteins usually carry the transmembrane segments in the $\mathrm{N}$-terminal part while the long catalytic relevant $\mathrm{C}$-tail is cytosolic. Our finding that most ATPases and some of the proteases of ' $\mathrm{Ca}$. P. mali' are predicted to be surface exposed is a new aspect in understanding phytoplasma pathogenicity at the sieve tube level. It might be possible that the powerful HflBs attack plasmalemma proteins of sieve tube elements, in particular if the phytoplasma cells are attached to the outer membrane. Attachment to host membranes is well established for most mycoplasmas pathogenic to humans and animals and is considered to be a prerequisite for colonization and infection (Razin et al. 1998). The same may be true for phytoplasmas. However, there are no firm data on such an attachment because this subject remains insufficiently investigated.

Based upon sequences of a variable AP464 fragment, we recently identified the separate clustering of virulent and mild strains that was associated with the presence of virulencerelated markers (Seemüller et al. 2011). To further investigate the putative phytopathogenic relevance of AAA+ proteins, we examined all distinct genes encoding these proteins in the AP agent in this study. The results show that, in four of six ATPases and three of five full-size HflBs, there were distinct differences in clustering and the presence of virulence-related substitutions between severe and mild strains. In both respects, the moderate strains showed an intermediate position by clustering inconsistently with severe strains and showing fewer substitutions. A different feature was shown by moderately virulent and periwinkle-maintained strain AT that always clustered with mild strains and did not have virulence-related substitutions similar to those found in other virulent strains. Instead, it differed from all other strains by a unique stretch of 37 amino
AP406_AT

AP406_3/3

AP406_2/7

AP406_2/4

AP406_1/93 Tab

AP406_1/93Vin

AP406_AP15

AP406_3/2

AP406_12/93

AP406_GDH4

AP406_AT-2

AP406_Rol

AP406_GDH6

AP406_3/1

AP406_3/6

AP406_3/8

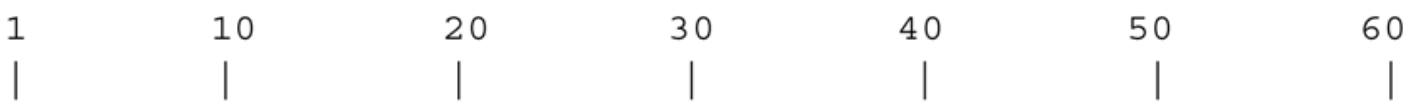

MSRKNTP - IEN- - - KTSKTKPIANNN-KFPSLVKINLILFIFSGLFISGFIYFLLLNTN MSRKNTP - IEN- - - KTSKTKPIANNN-KFPSLVKINLILF IFSGLFISGFIYFLLLNTN MSRKNTP - IEN- - - KTSKTKPIANNN-KFPSLVK INLILF IFSGLFISGF IYFLLLNTN MSRKNTP - IEN- - - KTSKTKPIANNN-KFPSLVKINLILFIFSGLFISGFIYFLLLNTN MSRKNTP - IEN- - - KTSKTKPIANNN-KFPSLVKINLILF IFSGLF ISGF IYFLLLNTN MSRKNTP - IEN--- -KTSKTKPIANNN-KFPSLVKINLILFIFSGLFISGFIYFLLLNTN MSRKNTP - IEN- - - KTSKTKPIANNN-KFPSLVKINLILFIFSGLF ISGF IYFLLLNTN MSRKNTP - IEN- - - KTSKTKPIANNN-KFPSLVKINLILFIFSGLFISGFIYFLLLNTN MSQKK IEKSENEEPQTNQETKP ITNNNIKFTSLVKINLILF IFA_GLF ISGF IYFLLLNTN MSQKKIEKSENEEPQTNQETKPITNNNIKFTSLVK INL ILF IFÄGLF ISGF I YFLLLNTN MSQKKIEKSENEEPQTNQETKPITNNNIKFTSLVKINLILF IFAGLF ISGF IYFLLLNTN MSQKKIEKSENEEPQTNQETKP ITNNNIKFTSLVK INLILF IFÄGLF I SGF IYFLLLNTN MSQKKIEKSENEEPQTNQETKPITNNNIKFTSLVKINLILF IFA슴 GLF ISGF IYFLLLNTN MSQKKIEKSENEEPQTNQETKP ITNNNIKFTSLVK INLILF IFA GLF ISGF I YFLLLNTN MSQKKIEKSENEEPQTNQETKPITNNNIKFTSLVK INLILF IFVGLFISGFIYFLLLNTN MSQKKIEKSENEEPQTNQETKP ITNNNIKFTSLVK INLILF I FÄ ALF I SGF IYFLLLNTN

Fig. 4. Alignment of deduced N-terminal sequences, including the transmembrane domain (positions 35 to 55) of AAA+ ATPase AP406 of 'Candidatus Phytoplasma mali' strains of different virulence. Sequences AP406_AT through AP406_3/2 are from mild strains from apple, periwinkle(1/93Vin), and tobacco (1/93Tab) and from periwinkle-maintained moderate strain AT and severe strain AP15. Sequences from AP406_12/93 through AP406_3/8 are from moderate (AT-2 and 3/8) and severe strains from apple. Black boxes indicate substitutions and insertions in severe and moderately virulent strains from apple.

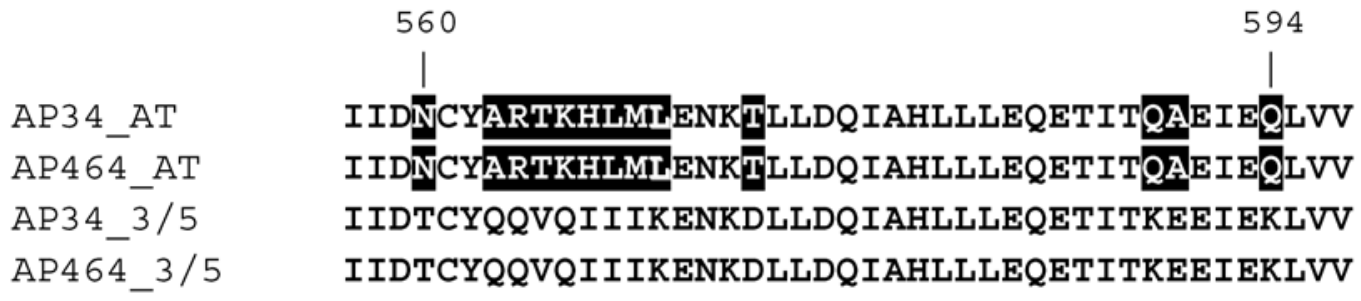

Fig. 5. Unique deduced protein sequence segments (position 560 to 594) in HflBs AP34 and AP464 of 'Candidatus Phytoplasma mali' strain AT with 13 substitutions (black boxes). AP34_3/5 and AP464_3/5 represent AP34 and AP464 sequences typical for other strains. 
acid residues that occurred at an identical position in the AP34 and AP464 proteins. It is conceivable that the occurrence of this segment is related to the long-time maintenance of this strain in periwinkle and may be involved in virulence.

Most of the substitutions observed in our work represent radical changes that affect the physicochemical properties of the amino acids. Usually, nonsynonymous nucleotide substitutions that change the physicochemical properties of amino acids occur with a lower rate than those that do not or little change the properties. This is consistent with the explanation that physicochemical properties of amino acids are relevant to protein function and that radical changes are more likely to be subject to the negative or purifying selection than conservative ones (Zhang 2000). Negative selection plays an important role not only in maintaining the long-term stability of biological structures by removing deleterious mutations but also in the survival of an organism. An example for the role on survival are host-parasite interactions. Here, host defense systems evolve to recognize a special structure on the parasite and allow its removal. This, in turn, induces negative selection on the current form of the parasite while leading to positive selection of variants that cannot be recognized by the host (Loewe 2009). Thus, in our case, negative selection may be beneficial for the pathogen and may support the hypothesis that the proteins predominantly showing radical replacements at the major substitution sites are involved in virulence.

Our data may also indicate evolutionary trends that may be relevant for virulence or fitness of the AP agent. Degeneration of cytosolic ATPase AP11 was observed where full-length genes were only amplified from mild and some moderate strains whereas only small gene fragments were amplified from severe strains. Similar-sized fragments together with full-length genes were also observed in some samples from mild and moderate strains. These findings may indicate that AP11 is degenerating and not involved in virulence and not crucially significant for cellular function. A more advanced state of degeneration was identified in the fragmented, putatively cytosolic AP454 protein gene as present in all strains. If the putatively virulence-related HflB AP464 has special functions and is involved in pathogenicity, AP457 would be the only major cytosolic HflB with general cellular functions similar to the single-copy $\mathrm{HflBs} / \mathrm{FtsHs}$ of other mollicutes and walled bacteria.

The presumption that the distinct clustering of AAA+ ATPase and HflB sequences of virulent and mild strains of ' $\mathrm{Ca}$. P. mali' and the presence of virulence-related substitutions indicate an involvement of these proteins in the AP phytoplasma pathogenicity is supported by the prediction that the enzyme-carrying C-tail of several of these proteins is oriented toward the sieve tubes. Thus, they may affect sieve tube function. Therefore, our results may encourage more intensive research on the AAA+ proteins and on pathogen-host interactions in the phytoplasma sieve tube environment. In particular, the predicted extracellular C-tail orientation requires experimental proof and, in due course, elucidation of the mode of action at the ultrastructural, histochemical, and molecular level. Another promising approach to examine the supposed involvement of the AAA+ proteins in AP phytoplasma pathogenicity is selection pressure analysis that is based on the ratio of nonsynonymous (amino-acid-altering) and synonymous (silent) substitutions. A clear positive selection on the proteins associated with strain virulence would imply their important role in pathogenesis (Kakizawa et al. 2006).

\section{MATERIALS AND METHODS}

\section{Phytoplasma sources.}

Twenty ' $\mathrm{Ca}$. P. mali' strains, each characterized to be a singlestrain accession in previous work (Seemüller et al. 2010, 2011) were included in this study (Table 1). With the exception of strains 1/93Tab, 1/93Vin, AP15, and AT-2, which originate from France or Italy, they were collected at the experimental field of the Julius Kuehn Institute (Dossenheim, Germany) or in surrounding areas (Table 1). The majority of the donor trees were observed in the field for at least 12 years. Then the strains were graft inoculated to $M 11$ rootstock and grown in an unheated greenhouse for 4 years. The disease history of the field-growing period of strains AT-2, Rol, WS, and the GDH group is largely unknown. At sampling, they were strongly symptomatic and were graft transmitted and grown in the greenhouse as described above. The scion cultivar of all trees was 'Golden Delicious'. Strains 1/93Vin and 1/93Tab were maintained in apple and the experimental hosts periwinkle and $N$. occidentalis, respectively. Strains AT and AP15 were previously transmitted from symptomatic apple trees to periwinkle (Carraro et al. 1988; Marwitz et al. 1974) and subsequently to tobacco using dodder (Cuscuta spp.) bridges. They were only available in these experimental hosts. Appearance and severity of disease symptoms of all greenhouse-maintained trees were annually recorded using a rating scheme from 0 to $3(0$, no symptom; 1 , foliar reddening; 2 , reduced vigor; and 3, witches' brooms or severe stunting). The cumulative symptom values of the trees were divided by the years of observation (Table 1). More information on disease rating, virulence, and the determination of the single-strain status of the accessions examined is provided elsewhere (Seemüller and Schneider 2007; Seemüller et al. 2010, 2011).

\section{DNA and RNA extraction, PCR amplification, cloning, sequencing, and cDNA synthesis.}

DNA was extracted from phloem preparations of the current season's shoot samples from ' $\mathrm{Ca}$. P. mali'-infected apple trees or leaf midribs of infected periwinkle and tobacco plants using a cetyltrimethylammonium bromide procedure, as described (Seemüller and Schneider 2007). For PCR amplification of the 10 distinct $\mathrm{AAA}+$ proteins, a range of primers were designed from the complete sequence of ' $\mathrm{Ca}$. P. mali' strain AT and a draft sequence of AP phytoplasma strain 1/93Tab (Kube et al. 2008; M. Kube, unpublished results) using Primer3 software (Rozen and Skaletsky 2000). Most primers derived from intergenic regions flanking the respective gene or from adjacent genes. If amplification with external primers was unsuccessful, they were combined with internal primers. Amplification was performed in $25-\mu \mathrm{l}$ reactions containing $0.5 \mu \mathrm{M}$ each primer, $1 \times$ polymerase buffer, $0.6 \mathrm{U}$ of $\mathrm{Taq}$ polymerase (Ampliqon, Copenhagen, Denmark), and $0.1 \mathrm{mM}$ each dNTP. The reaction was cycled with the following parameters: $5 \mathrm{~min}$ of initial denaturation at $95^{\circ} \mathrm{C}$ followed by 35 cycles at $95^{\circ} \mathrm{C}$ for $1 \mathrm{~min}, 52$ to $54^{\circ} \mathrm{C}$ for $45 \mathrm{~s}$, and $68^{\circ} \mathrm{C}$ for 1.5 to $2.0 \mathrm{~min}$. The final step was 5 min at $68^{\circ} \mathrm{C}$.

PCR products were sequenced using external and internal primers. In cases of variable product sizes or suspected truncated genes, amplification products were ligated into pGEM-T Easy vector system (Promega Corp., Madison, WI, U.S.A.) and were transformed to E. coli XL1 Blue cells (Stratagene, La Jolla, CA, U.S.A.). Colony PCR was employed to amplify the inserts of recombinant plasmids, using standard M13 primers. Clones were propagated in Luria Bertani medium. Recombinant plasmid DNA was extracted using a miniprep kit (Qiagen, Hilden, Germany) and the inserts were sequenced using M13 and internal primers. Designation of genes and deduced proteins refer to the corresponding genes of ' $\mathrm{Ca}$. P. mali' strain AT; for instance "AP34" for the ATP00034 homologs in other strains.

Total RNA from strain AT-infected and healthy N. occidentalis was extracted using a silica procedure followed by DNase 
treatment (Rott and Jelkmann 2001). cDNA synthesis and PCR amplification of reverse-transcription (RT)-DNA was performed using the OneStep RT-PCR kit (Qiagen).

\section{Phylogenetic and functional analysis.}

Alignment of DNA and deduced amino acid sequences was performed with ClustalX2 (Thompson et al. 1997). Phylogenetic analyses were conducted in MEGA4 using the neighborjoining parameters and the bootstrap test. The trees were drawn to scale, with branch lengths calculated using the average pathway method (Tamura et al. 2007). All information given in the text on the position of amino acid residues refers to the multiple alignments of all strains of the respective protein. To determine identity and relatedness of the deduced protein sequences, the Standard Protein BLAST (blastp) and PSI-Blast programs were employed (Altschul et al. 1997), using GenBank nonredundant protein sequence database (National Center for Biotechnology Information [NCBI], National Institute of Health, Bethesda, MD, U.S.A.). The Conserved Domain Architecture Tool (CDART) program (Geer et al. 2002), available in the NCBI BLAST applications, was also included in the study. Prediction of membrane topology, in particular the number of transmembrane domains and the spatial orientation of the $\mathrm{C}$ terminal tail, was performed using the Phobius and PolyPhobius predictors (Käll et al. 2004, 2007). All amino acid sequences were examined for their number of transmembrane segments and C-tail orientation using the Phobius approach. A reduced number of sequences from severe or moderate and mild strains was examined from each protein employing the PolyPhobius program. The presence of signal peptides was examined in all sequences using the SignalP 4.0 software (Petersen et al. 2011) and the Phobius program.

The type of amino acid replacement in nonsynonymous substitutions was examined by using a combination of ClustalX2 alignments (Thompson et al. 1997) and the criteria employed by Dagan and associates (2002) to distinguish conservative replacements (not or little affecting protein properties) from radical substitutions that alter the physicochemical properties of the protein. The possible amino acid replacements were classified using two independent criteria: i) charge and ii) volume and polarity. Classification by charge was made by dividing the amino acids into three categories: positive $(\mathrm{R}, \mathrm{H}$, and $\mathrm{K}$ ), negative (D and E), and uncharged (A, N, C, Q, G, I, L, M, F, P, S, T, W, Y, and V). Classification by volume and polarity was made by dividing the amino acids into six categories: special (C), neutral and small (A, G, P, S, and T), polar and relatively small (N, D, Q, and E), polar and relatively large $(\mathrm{R}, \mathrm{H}$, and $\mathrm{K}$ ), nonpolar and relatively small (I, L, M, and V), and nonpolar and relatively large $(\mathrm{F}, \mathrm{W}$, and $\mathrm{Y})$. Within each of the two classifications, amino acid replacements were deemed conservative if they involved exchanges within a category and radical if the exchanges occurred among categories. Only major substitution sites important for the discrimination of severe and mild strains were considered in the evaluation.

\section{ACKNOWLEDGMENTS}

This work was supported by the IASMA Research Center at S. Michele all'Adige (Italy) and the Alexander von Humboldt Foundation. S. Sule gratefully acknowledges the fellowship provided by the Alexander von Humboldt Foundation for his stay at the Julius Kuehn Institute. E. Seemüller, B. Schneider, S. Sule, and M. Kube carried out the work and drafted the manuscript. All authors contributed to the conception and design of the research and to the critical revision and final approval of the version to be published. We thank L. Tran-Nguyen and R. Herrmann for critical reading of the manuscript and helpful suggestions; F. Hergenhahn, M. Kampmann, and T. Schneider for technical support; and B. Ding and an anonymous reviewer for improving the quality of the manuscript.

\section{LITERATURE CITED}

Akiyama, Y., Kihara, A., Tokuda, H., and Ito, K. 1996. FtsH (HflB) is an ATP-dependent protease selectively acting on SecY and some other membrane proteins. J. Biol. Chem. 271:31196-32201.

Alix, E., and Blanc-Potard, A. B. 2008. Peptide-assisted degradation of the Salmonella MgtC virulence factor. EMBO (Eur. Mol. Biol. Organ.) J. 27:546-557.

Altschul, S. F., Madden, T. L., Schaffer, A. A., Zhang, J., Zhang, Z., Miller, W., and Lipman, D. J. 1997. Gapped BLAST and PSI-BLAST: A new generation of protein database search programs. Nucleic Acids Res. 25:3389-3402.

Arashida, R., Kakizawa, S., Hoshi, A., Ishii, Y., Jung, H. Y., Kagiwada, S., Yamaji, Y., Oshima, K., and Namba, S. 2008. Heterogeneic dynamics of the structures of multiple gene clusters in two pathogenetically different lines originating from the same phytoplasma. DNA Cell Biol. 27:209217.

Bai, X., Zhang, J. H., Ewing, A., Miller, S. A., Radek, A. J., Shevchenko, D. V., Tsukerman, K., Walunas, T., Lapidus, A., Campbell, J. W., and Hogenhout, S. A. 2006. Living with genome instability: The adaptation of phytoplasmas to diverse environments of their insect and plant hosts. J. Bacteriol. 188:3682-3696.

Batjer, L. P., and Schneider, H. 1960. Relation of pear decline to rootstocks and sieve-tube necrosis. Proc. Am. Soc. Hortic. Sci. 76:85-97.

Blodgett, E. C., Schneider, H., and Aichele, M. D. 1962. Behavior of pear decline disease on different stock-scion combinations. Phytopathology 52:679-684.

Braun, E. J., and Sinclair, W. A. 1976. Histopathology of phloem necrosis in Ulmus americana. Phytopathology 66:598-607.

Braun, E. J., and Sinclair, W. A. 1978. Translocation in phloem necrosisdiseased American elm seedlings. Phytopathology 68:1733-1737.

Carraro, L., Osler, R., Refatti E., and Poggi Pollini, C. 1988. Transmission of the possible agent of apple proliferation to Vinca rosea by dodder. Riv. Patol. Veg. Ser. 4 24:43-52.

Chiba, S., Akiyama, Y., and Ito, K. 2002. Membrane protein degradation by FtsH can be initiated from either end. J. Bacteriol. 184:4775-4782.

Dagan, T., Talmor, Y., and Graur, D. 2002. Ratios of radical to conservative amino acid replacement are affected by mutational and compositional factors and may not be indicative of positive Darwinian selection. Mol. Biol. Evol. 19:1022-1025.

Erzberger, J. P., and Berger, J. M. 2006. Evolutionary relationships and structural mechanisms of AAA+ proteins. Annu. Rev. Biophys. Biomol. Struct. 35:93-114.

Geer, L. Y., Domrachev, M., Lipman, D. J., and Bryant, S. H. 2002. CDART: Protein homology by domain architecture. Genome Res. 12:1619-1623.

Hanson, P. I., and Whiteheart, S. W. 2005. AAA+ proteins: Have engine, will work. Nat. Rev. Mol. Cell Biol. 6:519-529.

Ito, K., and Akiyama, Y. 2005. Cellular functions, mechanism of action, and regulation of FtsH protease. Annu. Rev. Microbiol. 59:211-231.

Kakizawa, S., Oshima, K., Jung, H. Y., Suzuki, S., Nishigawa, H., Arashida, R., Miyata, S., Ugaki, M., Kishino, H., and Namba, S. 2006. Positive selection acting on a surface membrane protein of the plantpathogenic phytoplasmas. J. Bacteriol. 188:3424-3428.

Käll, L., Krogh, A., and Sonnhammer, E. L. L. 2004. A combined transmembrane topology and signal peptide prediction method. J. Mol. Biol. 338:1027-1036.

Käll, L., Krogh, A., and Sonnhammer, E. L. L. 2007. Advantages of combined transmembrane topology and signal peptide prediction-The Phobius web server. Nucleic Acids Res. 35 (Suppl. 2):W429-W432.

Karata, K., Verma, C. S., Wilkinson, A. J., and Ogura, T. 2001. Probing the mechanism of ATP hydrolysis and substrate translocation in the AAA protease FtsH by modelling and mutagenesis. Mol. Microbiol. 39:890903.

Kartte, S., and Seemüller, E. 1991. Histopathology of apple proliferation in Malus taxa and hybrids of different susceptibility. J. Phytopathol. 131:149-160.

Kube, M., Schneider, B., Kuhl, H., Dandekar, T., Heitmann, K., Migdoll, A., Reinhardt, R., and Seemüller, E. 2008. The linear chromosome of the plant-pathogenic mycoplasma 'Candidatus Phytoplasma mali'. BMC Genomics 9:306

Langklotz, S., Baumann, U., and Narberhaus, F. 2012. Structure and function of the bacterial AAA protease FtsH. Biochim. Biophys. Acta 1823:40-48.

Lepka, P., Stitt, M., Moll, E., and Seemüller, E. 1999. Effect of phytoplasmal infection on concentration and translocation of carbohydrates and amino acids in periwinkle and tobacco. Physiol. Mol. Plant Pathol. 55:59-68.

Lithgow, J. K., Ingham, E., and Foster, S. J. 2004. Role of the hprT-ftsH locus in Staphylococcus aureus. Microbiology 150:373-381.

Loewe, L. 2009. A framework for evolutionary systems biology. BMC 
Syst. Biol. 3:27.

Marwitz, R., Petzold, H., and Özel, M. 1974. Untersuchungen zur Übertragbarkeit des möglichen Erregers der Triebsucht des Apfels auf einen krautigen Wirt. Phytopathol. Z. 81:85-91.

Oshima, K., Kakizawa, S., Nishigawa, H., Jung, H. Y., Wei, W., Suzuki, S., Arashida, R., Nakata, D., Miyata, S., Ugaki, M., and Namba, S. 2004. Reductive evolution suggested from the complete genome sequence of a plant-pathogenic phytoplasma. Nat. Genet. 36:27-29.

Petersen, T. N., Brunak, S., Heinje, G., and Nielsen, H. 2011. SignalP 4.0: Discriminating signal peptides from transmembrane regions. Nat Methods 8:785-786.

Razin, S., Yogev, D., and Naot, Y. 1998. Molecular biology and pathogenicity of mycoplasmas. Microbiol. Mol. Biol. Rev. 62:1094-1156.

Rott, M. E., and Jelkmann, W. 2001. Characterization and detection of several filamentous viruses of cherry: Adaptation of an alternative cloning method (DOP-PCR), and modification of an RNA extraction protocol. Eur. J. Plant Pathol. 107:411-420.

Rozen, S., and Skaletsky, H. J. 2000. Primer3 on the WWW for general users and for biologist programmers. Pages 365-386 in: Bioinformatics Methods and Protocols: Methods in Molecular Biology. S. Krawetz and S. Misener, eds. Humana Press, Totowa, NJ, U.S.A.

Schneider, B., and Seemüller, E. 2009. Strain differentiation of Candidatus Phytoplasma mali by SSCP and sequence analyses of the $h f l \mathrm{~B}$ gene. J. Plant Pathol. 91:103-112.

Seemüller, E., and Schneider, B. 2007. Differences in virulence and genomic features of strains of 'Candidatus Phytoplasma mali', the apple proliferation agent. Phytopathology 97:964-970.

Seemüller, E., Garnier, M., and Schneider, B. 2002. Mycoplasmas of plants and insects. Pages 91-116 in: Molecular Biology and Pathology of Mycoplasmas. S. Razin and R. Herrmann, eds. Kluwer Academic/ Plenum Publishers, London.

Seemüller, E., Kiss, E., Sule, S., and Schneider, B. 2010. Multiple infection of apple trees by distinct strains of 'Candidatus Phytoplasma mali' and its pathological relevance. Phytopathology 100:863-870.

Seemüller, E., Kampmann, M. Kiss, E., and Schneider, B. 2011. HfIB genebased phytopathogenic classification of 'Candidatus Phytoplasma mali' strains and evidence that strain composition determines virulence in multiply infected apple trees. Mol. Plant-Microbe Interact. 24:1258-1266.

Siller, W., Kuhbandner, B., Marwitz, R., Petzold, H., and Seemüller, E. 1987. Occurrence of mycoplasma-like organisms in parenchyma cells of Cuscuta odorata (Ruiz et Pav.). J. Phytopathol. 119:147-159.

Snider, J., Thibault, G., and Houry, W. A. 2008. The AAA+ superfamily of functionally diverse proteins. Genome Biol. 9:216.

Tamura, K., Dudley, J., Nei, M., and Kumar, S. 2007. MEGA4: Molecular evolutionary genetics analysis (MEGA) software version 4.0. Mol. Biol. Evol. 24:1596-1599.

Thompson, J. D., Gibson, T. J. Plewniak, F., Jeanmougin, F., and Higgins, D. G. 1997. The ClustalX windows interface: Flexible strategies for multiple sequence alignment aided by quality analysis tools. Nucleic Acids Res. 24:4876-4882.

Tran-Nguyen, L. T. T., Kube, M., Schneider, B., Reinhardt, R., and Gibb, K. S. 2008. Comparative genome analysis of 'Candidatus Phytoplasma australiense' (subgroup tuf-Australia I; rp-A) and ' $\mathrm{Ca}$. Phytoplasma asteris' strains OY-M and AY-WB. J. Bacteriol. 190:3979-3991.

Zhang, J. 2000. Rates of conservative and radical nonsynonymous nucleotide substitutions in mammalian nuclear genes. J. Mol. Evol. 50:56-68. 